\title{
Effect of Heparin-Protamine Treatment on Thyroid Cancer Cell Lines
}

\author{
ATSUSHI FUSHIMI ${ }^{1,2}$, HIROSHI TAKEYAMA ${ }^{2}$ and YOSHINOBU MANOME ${ }^{1}$ \\ ${ }^{I}$ Division of Molecular Cell Biology, Core Research Facilities of Basic Science, \\ The Jikei University School of Medicine, Tokyo, Japan; \\ ${ }^{2}$ Department of Surgery, The Jikei University School of Medicine, Tokyo, Japan
}

\begin{abstract}
Background: Anticoagulation therapy is often used to prevent stroke in patients with thyroid cancer. However, the effects of heparin and protamine on thyroid cancer are unknown; therefore, we examined the response of thyroid cancer cell lines to heparin and protamine. Materials and Methods: Cytotoxic assay for heparin-protamine treatment was examined on SW1736, 8505c and 8305c cell lines. Results: The half-maximal inhibitory concentration of the heparin-protamine treatment was $82.1 \mu \mathrm{g} / \mathrm{ml}$ for the SW1736 cell line, $10.4 \mu \mathrm{g} / \mathrm{ml}$ for $8505 \mathrm{c}$, and $17.8 \mu \mathrm{g} / \mathrm{ml}$ for 8305c. Each cell line expresses fibronectin, with SW1736 expressing mutant fibronectin; thus, it is possible that mutant fibronectin may prevent the antitumor effect in SW1736 cells. Conclusion: The SW1736 cell line did not show any antitumor effect after heparin-protamine treatment. Further research is needed on why heparin-protamine treatment does not exert an antitumor effect on SW1736 cells, and the results of this research could mean that the heparinprotamine treatment might be used to provide antitumor effects in some thyroid cancer cases.
\end{abstract}

Surgery, thyroid hormone therapy, radiation iodine therapy, and chemotherapy are routinely used to treat progressive thyroid cancer. It is important to monitor patients during thyroid cancer treatment for signs of stroke so that these treatments can be continued to optimize long-term prognosis. Stroke onset in patients with cancer is due to a variety of reasons, including hypercoagulability, tumor compression, and anticancer drugs (1). Furthermore, anti-coagulation therapy is often used to prevent stroke in patients with thyroid cancer with atrial fibrillation because such patients are at increased

Correspondence to: Atsushi Fushimi, Division of Molecular Cell Biology, Core Research Facilities of Basic Science, The Jikei University School of Medicine, Tokyo, Japan. Tel: +81334331111 , Fax: +81 354001387, e-mail: fushimi@jikei.ac.jp

Key Words: Heparin, protamine, thyroid cancer. risk of atrial fibrillation (2). Protamine is often used as a heparin antagonist after heparin replacement before surgical treatment. However, it is unknown whether heparin and protamine have positive or negative effects on thyroid cancer.

Some studies have been conducted on the antitumor effects of heparin or protamine. Falanga and Marchetti demonstrated that the antitumor effect of heparin occurs through inhibition of thrombin generation and fibrin formation(3). Furthermore, Taylor and Folkman showed the antitumor effect of protamine was through inhibition of tumor angiogenesis (4). Therefore, the highly popular heparin-protamine treatment, in which protamine is administered as an antagonist of heparin, may also provide antitumor effects. However, the effect of heparin and protamine treatment on thyroid cancer cells themselves is unknown. Here we examined cell proliferation in thyroid cancer cell lines after heparin and protamine treatment.

\section{Materials and Methods}

Cell culture and reagents. SW1736 human thyroid cancer cells (American Type Culture Collection, Manassas, VA, USA) were cultured in Leibovitz's medium supplemented with $10 \%$ fetal bovine serum (FBS). 8305c and 8505c human thyroid cancer cells (American Type Culture Collection) were cultured in Roswell Park Memorial Institute medium supplemented with 10\% FBS. All cell lines were maintained in an incubator at $3{ }^{\circ} \mathrm{C}$ with $5 \% \mathrm{CO}_{2}$. In the experiments in which heparin or protamine were added, cells were cultured without FBS because FBS reacts with both heparin and protamine. Preliminary experiments confirmed that the ability of these cell lines to proliferate did not change even without the addition of FBS. Sodium heparin was obtained from Wako Pure Chemical Industries, Ltd. (Osaka, Japan) and protamine sulfate from MP Biomedicals (Santa Ana, CA, USA).

Cell growth curve. SW 1736, 8305c, and 8505c cell lines were plated into $25 \mathrm{~cm}^{2}$ flasks in medium containing FBS at a cell density of $5.0 \times 10^{4}$ cells $/ \mathrm{ml}$. The number of viable cells was counted every $24 \mathrm{~h}$ using trypan blue for 9 days. The cell growth curve was drawn using the mean of experiments performed in triplicate, and the doubling time and saturation density of each cell type were calculated. 
Table I. Characteristics of the human anaplastic thyroid carcinoma cell lines used in this study.

\begin{tabular}{|c|c|c|c|c|c|}
\hline \multirow[t]{2}{*}{ Cell line } & \multicolumn{2}{|c|}{ Cell growth curve } & \multicolumn{3}{|c|}{ Cell-cycle distribution } \\
\hline & Doubling time $(\mathrm{h})$ & Saturation density $\left(\times 10^{4}\right.$ cells $\left./ \mathrm{cm}^{2}\right)$ & $\mathrm{G}_{1} / \mathrm{G}_{0}(\%)$ & $\mathrm{S}(\%)$ & $\mathrm{G}_{2} / \mathrm{M}(\%)$ \\
\hline SW1736 & $29.7 \pm 7.2$ & $9.73 \pm 1.7$ & $78.2 \pm 2.2$ & $3.9 \pm 0.4$ & $17.3 \pm 3.2$ \\
\hline $8505 c$ & $36.9 \pm 7.1$ & $25.5 \pm 1.9$ & $59.5 \pm 1.5$ & $8.8 \pm 1.9$ & $30.7 \pm 1.0$ \\
\hline $8305 \mathrm{c}$ & $29.5 \pm 9.2$ & $11.3 \pm 1.4$ & $60.2 \pm 1.8$ & $7.8 \pm 2.4$ & $31.0 \pm 1.1$ \\
\hline
\end{tabular}

Cell-cycle analysis. SW1736, 8305c, and 8505c cell lines were seeded into $25 \mathrm{~cm}^{2}$ flasks at a cell density of $1.0 \times 10^{5}$ cells $/ \mathrm{ml}$ for 9 days. The cell-cycle distribution of the cells was analyzed during the log phase. After cell detachment with trypsin, 75\% ethanol was added to fix the cells overnight. The cells were washed with phosphate-buffered saline, $180 \mathrm{U}$ RNAse and $50 \mu \mathrm{M}$ propidium iodide (PI) were added, and the cells were then incubated at room temperature for $30 \mathrm{~min}$. Cells were analyzed using flow cytometry (FACScan; Becton Dickinson, Franklin Lakes, NJ, USA).

Cytotoxic assay for heparin. SW1736, 8305c, and 8505c cell lines were seeded onto 96-well plates at a cell density of $1.0 \times 10^{5}$ cells $/ \mathrm{ml}$. Heparin was added at concentrations of $0.2-100$ units $/ \mathrm{ml}$, and the MTT assay was carried out because methylene blue reacts with high concentrations of heparin. After $72 \mathrm{~h}$ of incubation without FBS, $5 \mathrm{mg} / \mathrm{ml}$ MTT solution was added, and the samples were incubated for $4 \mathrm{~h}$. Acid isopropanol $(0.04 \mathrm{~N})$ was then added to dissolve blue formazan crystals. The eluted solution was examined at $570 \mathrm{~nm}$ using a microplate reader (Bio-Rad, Hercules, CA, USA), and the percentage of viable cells was then calculated.

Cytotoxic assay for the heparin-protamine treatment. SW1736, $8305 \mathrm{c}$, and $8505 \mathrm{c}$ cell lines were seeded onto 96 -well plates at a cell density of $1.0 \times 10^{5}$ cells $/ \mathrm{ml}$. Heparin $(10 \mathrm{units} / \mathrm{ml})$ was added, and the samples were incubated for $24 \mathrm{~h}$. After removing the medium containing heparin, protamine was added at concentrations of $5-108 \mu \mathrm{g} / \mathrm{ml}$. The cells were incubated for $72 \mathrm{~h}$. We defined this series of steps as the heparin-protamine treatment. Glutaraldehyde $(25 \%)$ was added to fix the cells, and the fixing solution was then removed. Methylene blue $(0.05 \%)$ was added to stain the viable cells. Elute by $0.33 \mathrm{~N} \mathrm{HCl}$ for $15 \mathrm{~min}$ was examined at $595 \mathrm{~nm}$ using a microplate reader (Bio-Rad). The half-maximal inhibitory concentration $\left(\mathrm{IC}_{50}\right)$ of each cell line was calculated for the heparin and protamine treatment.

Coomassie blue staining and western blotting of fibronectin. SW1736, 8305c, and $8505 \mathrm{c}$ cell lines were seeded into $25 \mathrm{~cm}^{2}$ flasks at a cell density of $1.0 \times 10^{5}$ cells $/ \mathrm{ml}$ for 3 days. The supernatant of each cell culture was heated at $100^{\circ} \mathrm{C}$ for $5 \mathrm{~min}$ with SDS sample buffer, and $10 \mu \mathrm{g}$ of protein was electrophoresed in 5\% acrylamide gel at $150 \mathrm{~V}$ for $1 \mathrm{~h}$.

For the Coomassie blue staining, one gel was fixed with $50 \%$ $(\mathrm{v} / \mathrm{v})$ methanol and $10 \%(\mathrm{v} / \mathrm{v})$ acetic acid; stained with $0.25 \%(\mathrm{w} / \mathrm{v})$ Coomassie Brilliant Blue R, 40\% (v/v) methanol, and 7\% (v/v) acetic acid; and then decolorized with $5 \%(\mathrm{v} / \mathrm{v})$ methanol and $7 \%$ (v/v) acetic acid. The gel was analyzed with ChemiDoc Touch (BioRad) which enables simultaneous qualitative and quantitative assay.
For the western blot, the other gel was blotted to a cellulose nitrate membrane at $150 \mathrm{~mA}$. Fibronectin Monoclonal Antibody (FN3) (eBioscience, San Diego, CA, USA) diluted 1,000 times was used as the primary antibody, and Anti-Mouse IgG HRP (GE Healthcare, Chicago, IL, USA) diluted 1,000 times was used as the secondary antibody. After adding Thermo Pierce Western Blotting Substrate (Thermo Fisher Scientific, Waltham, MA, USA), the image was acquired with chemiluminescence detection using ChemiDoc Touch (Bio-Rad).

\section{Results}

Table I shows the characteristics of the cell lines in this study. Although no significant difference was found in the doubling time among the cell lines, the saturation density of $8505 \mathrm{c}$ was slightly higher than that of the other cell lines. The results of PI staining show that there were no significant differences in the cell-cycle distribution, although SW1736 tended to have a higher $\mathrm{G}_{1} / \mathrm{G}_{0}$ and lower $\mathrm{G}_{2} \mathrm{M}$ proportions than the other two cell lines. These results indicate that there were no significant differences in the basic characteristics of these cell lines.

Heparin had no antitumor effect on the thyroid cancer cell lines in the concentration range tested in this study (Figure 1). Therefore, we decided to use $10 \mathrm{U} / \mathrm{ml}$ of heparin because it is relatively close to the concentrations used in clinical practice and because it had no antitumor effect on the cells in the heparin-protamine treatment experiment.

The heparin-protamine treatment had a significantly lower antitumor effect on SW1736 than on 8305 c and 8505 c cells (Figure 2). The $\mathrm{IC}_{50}$ values in the heparin-protamine treatment were $82.1 \mu \mathrm{g} / \mathrm{ml}$ for SW1736, $10.4 \mu \mathrm{g} / \mathrm{ml}$ for $8505 \mathrm{c}$, and $17.8 \mu \mathrm{g} / \mathrm{ml}$ for $8305 \mathrm{c}$. Conversely, the $\mathrm{IC}_{50}$ values of protamine without heparin were $93.6 \mu \mathrm{g} / \mathrm{ml}$ for SW1736, $9.6 \mu \mathrm{g} / \mathrm{ml}$ for $8505 \mathrm{c}$, and $13.1 \mu \mathrm{g} / \mathrm{ml}$ for $8305 \mathrm{c}$. The reason for this may be that heparin and protamine reacted with the extracellular matrix.

Next, we considered the protein levels in the supernatant of the cultured cells. Coomassie blue staining showed bands above $250 \mathrm{kDa}$ for all three cell lines, although the band for $8505 \mathrm{c}$ was only slightly stained (Figure 3 ). All of these are thyroid cancer cell lines; however, an important difference among these cell lines is that SW1736 releases a modulated type of fibronectin 


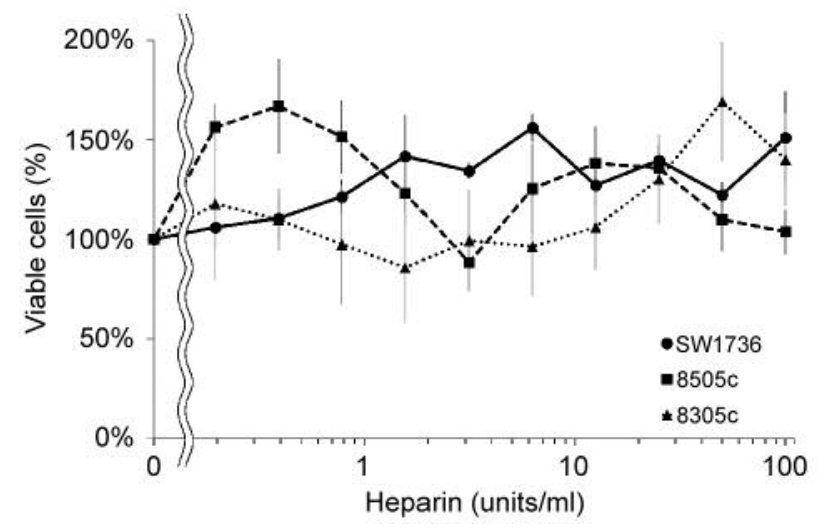

Figure 1. MTT assay for the effect of heparin on the $8305 c, 8505 c$, and SW1736 cell lines. The assay was measured at $570 \mathrm{~nm}$ after the addition of $5 \mathrm{mg} / \mathrm{ml}$ of MTT solution following $72 \mathrm{~h}$ of incubation in medium without fetal bovine serum.

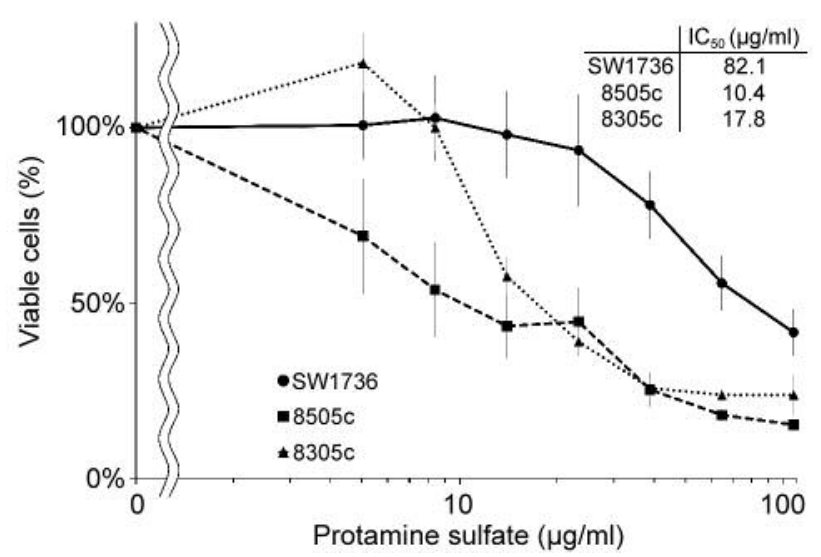

Figure 2. Cytotoxic assay using methylene blue for heparin-protamine treatment of $8305 c, 8505 c$, and SW1736 cell lines. Methylene blue $(0.05 \%)$ was added, followed by 10 units $/ \mathrm{ml}$ of heparin for $24 \mathrm{~h}$, and protamine was then added for $84 \mathrm{~h}$ at concentrations of 5-108 $\mu \mathrm{g} / \mathrm{ml}$; optical density of the samples was then measured at $595 \mathrm{~nm} . \mathrm{IC}_{50}$ : Halfmaximal inhibitory concentration.
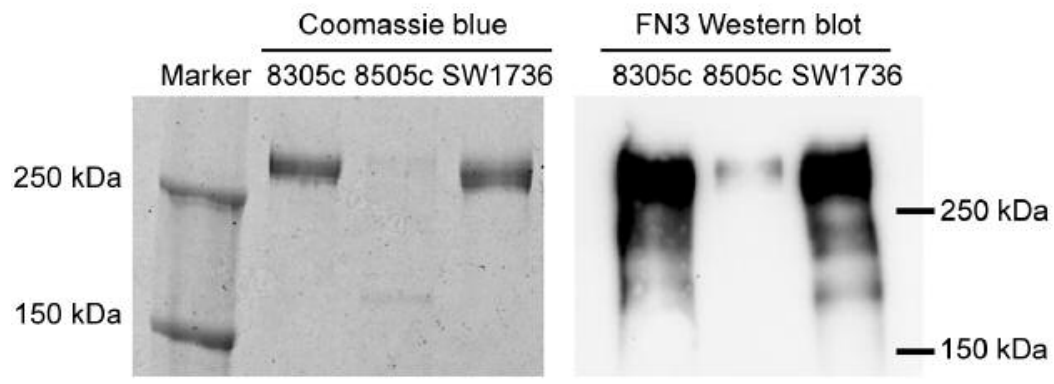

Figure 3. Coomassie blue staining and fibronectin western blot for 8305c, 8505c, and SW1736 cell lines. Coomassie blue staining was performed using $0.25 \%(w / v)$ Brilliant Blue R, 40\% (v/v) methanol, and 7\% (v/v) acetic acid. For the western blot, fibronectin monoclonal antibody (FN3) was used as the primary antibody, and Anti-Mouse IgG HRP was used as the secondary antibody.

(5). Western blotting of the cell culture supernatant was performed using anti-FN3 because most of the protein in the cell culture supernatant was expected to be fibronectin. Strong bands were detected above $250 \mathrm{kDa}$ for SW1736 and 8305c, and weak bands were detected above $250 \mathrm{kDa}$ for $8505 \mathrm{c}$. Because the results of Coomassie blue staining and western blotting were correlated, we deduced that most of the protein released in the extracellular matrix for these cell lines was fibronectin.

\section{Discussion}

Our results revealed that heparin did not have any antitumor effect on these thyroid cancer cell lines and that the heparinprotamine treatment did not have any antitumor effect on one of these cell lines, SW1736, compared with 8305c and 8505c.
Several mechanisms have been suggested for the antitumor effect of heparin (3). Heparin inhibits the formation of both thrombin and fibrin. Thrombin is a serine protease that promotes tumor growth (6), whereas fibrin clots play a role in protecting cancer cells from attack by the immune system (7). Although we expected heparin to have an antitumor effect, our results showed that heparin had almost no cytocidal effect on these cells itself.

Protamine is clinically used as an antagonist of heparin. Therefore, in this study, we evaluated the antitumor effect on thyroid cancer cell lines of heparin-protamine treatment, in which protamine was administered after heparin. We selected SW1736, 8305c, and 8305c, which are common thyroid cancer cell lines. Table I shows that there was no significant bias in cell proliferation among the three cell lines. Although 
we predicted that there would be no difference among these cell lines regarding their response to the heparin-protamine treatment, we found a significantly lower antitumor effect of this treatment on SW1736 cells than on 8305c and 8505c cells (Figure 2).

We inferred that the antitumor effect of the heparinprotamine treatment is related to the function of protamine in the extracellular matrix; therefore, we examined the proteins in the cell culture supernatant. The size of the band on Coomassie blue staining was the same as that on western blotting with the FN3 antibody and there was no other band in Coomassie blue staining. Coomassie blue staining and western blotting showed that most of the proteins released outside the cell were proteins of approximately $250 \mathrm{kDa}$, which suggests that fibronectin is released by these cell lines, Fibronectin may be related to the antitumor effect exerted by the heparin-protamine treatment because fibronectin has a heparin-binding site and heparin-like glycosylation (8).

SW1736 is known to release a mutant type of fibronectin $(5,9)$. Takeyama et al. discovered that monoclonal JT-95 antibody recognizes the fibronectin produced by SW1736 cells (5). Antigens that react with this antibody are known to be expressed in most papillary thyroid carcinomas. Another study used Papanicolaou staining to show that $95 \%$ of the papillary thyroid carcinomas that they tested were positive for JT-95; positive rates were low in follicular carcinoma and other benign thyroid diseases(10). Additionally, $51 \%$ of primary papillary carcinomas and $80 \%$ of recurrent and metastatic papillary carcinomas secrete a mutant type of fibronectin into the bloodstream (11). Another study also showed JT-95 positivity to be associated with lymph node metastasis (12); thus, the JT-95 antigen may be involved in metastasis and malignancy in thyroid cancer. However, this antibody does not recognize normal fibronectin as produced by $8305 \mathrm{c}$ and $8505 \mathrm{c}$ cells.

The antigen for this JT-95 antibody is presumed to be a large repetitive type of sugar chain containing sialic acid. Because its glycosylation site is near the heparin-binding site on fibronectin, this sugar chain may affect binding of heparin and protamine to fibronectin. This may be why the SW1736 cell line was less affected by the heparin-protamine treatment in this study relative to the other two cell lines.

In conclusion, heparin-protamine treatment had a less antitumor effect on SW1736 cells than on 8305c and 8505c cells. Furthermore, no antitumor effect was observed on any of the three cell lines in the heparin concentration range used in clinical practice. The heparin-protamine treatment might be useful for treating thyroid cancer in the future by ascertaining the reason why this treatment had a less antitumor effect on SW1736 cells.

\section{References}

1 Dearborn JL, Urrutia VC and Zeiler SR: Stroke and cancer - a complicated relationship. J Neurol Transl Neurosci 2(1): 1039, 2014.

2 Klein Hesselink EN, Lefrandt JD, Schuurmans EP, Burgerhof JG, Groen B, Gansevoort RT, van der Horst-Schrivers AN, Dullaart RP, Van Gelder IC, Brouwers AH, Rienstra M and Links TP: Increased risk of atrial fibrillation after treatment for differentiated thyroid carcinoma. J Clin Endocrinol Metab 100(12): 4563-4569, 2015.

3 Falanga A and Marchetti M: Heparin in tumor progression and metastatic dissemination. Semin Thromb Hemost 33(7): 688694, 2007.

4 Taylor S and Folkman J: Protamine is an inhibitor of angiogenesis. Nature 297(5864): 307-312, 1982.

5 Takeyama H, Hosoya T, Sakurai K, Mori Y, Watanabe M, Kisaki $\mathrm{H}$ and Ohno T: Production of a novel monoclonal antibody, JT95, which can detect antigen of thyroid carcinoma. Cancer Res 56(8): 1817-1822, 1996.

6 Tsopanoglou NE and Maragoudakis ME: Role of thrombin in angiogenesis and tumor progression. Semin Thromb Hemost 30(1): 63-69, 2004.

7 Palumbo JS, Talmage KE, Massari JV, La Jeunesse CM, Flick MJ, Kombrinck KW, Jirouskova M and Degen JL: Platelets and fibrin(ogen) increase metastatic potential by impeding natural killer cell-mediated elimination of tumor cells. Blood 105(1): 178-185, 2005.

8 Wierzbicka-Patynowski I and Schwarzbauer JE: The ins and outs of fibronectin matrix assembly. J Cell Sci 116(Pt 16): 32693276, 2003

9 Kimura N, Kurokawa K, Yamamoto K, Narimatsu H, Kimura H, Hosoya $\mathrm{T}$ and Takeyama H: Molecular identification of the antigens recognized by monoclonal antibody JT95 specific for thyroid carcinomas. Biochem Biophys Res Commun 251(2): 449-453, 1998.

10 Hosoya $\mathrm{T}$ and Sakurai K: Histochemical response of papillary thyroid carcinomas to the monoclonal antibody (JT-95). Jpn J Cancer Clin 37(7): 721-724, 1991.

11 Takeyama H: A trial for selective molecular therapy of thyroid papillary carcinoma using JT-95 antibody conjugated ${ }^{131}$ I. Jpn J Cancer Clin 50(10): 825-830, 2004.

12 Takeyama H, Kyoda S, Okamoto T, Manome Y, Watanabe M, Kinoshita S, Uchida K, Sakamoto A and Morikawa T: The expression of sialic fibronectin correlates with lymph node metastasis of thyroid malignant neoplasmas. Anticancer Res 31(4): 1395-1398, 2011.
Received October 31, 2018

Revised November 10, 2018

Accepted November 14, 2018 